\title{
NEW PHYSICS LABORATORY OF THE UNIVERSITY OF READING
}

\begin{abstract}
$\mathrm{T}$
HE new physics laboratory of the University of Reading was opened on May 17 by Sir George Thomson, who named the building "The J. J. Thomson Physical Laboratory". On the occasion of the opening, honorary degrees were conferred on Dr. T. E. Allibone, Prof. N. F. Mott, Prof. F. Seitz and Sir George Thomson. It is of interest to recall that Sir J. J. Thomson received an honorary degree from the University in 1935 and that both the first professor of physies at the University of Reading (J. A. Crowther) and the present professor (R. W. Ditchburn) worked in the Cavendish Laboratory under him.

The Laboratory was planned to accommodate undergraduate classes of up to 100 in each of the first two years (post-intermediate), and about thirty in the special honours final year. Facilities for about fifty research workers (including members of staff) were also provided. It was expected that the intermediate science class would be very small, but that teaching at this level would be required for about 100 students in agriculture, etc. It now appears probablo
\end{abstract}

that the numbers of students in theso elementary classes will be much smaller than was expected, but the teaching laboratory space released will be required to deal with the large increase of students now predicted for the next decade.

The Laboratory is a three-storey steel-framed building with a floor area of about $63,000 \mathrm{sq}$. ft. The structure has brown-grey brick walls and the greater part has a low pitch roof covered in copper. The western end of the Laboratory, connected to the main building by a two-storey glazed link, is the lecture theatre block. This has a flat roof surrounded by a parapet wall. The ground floor contains two lecture theatres, with a projection room for each and a preparation room common to both. On the first floor, above the lecture theatres, are two large teaching laboratories for the general honours students and for special honours students in their first and second years. These laboratories cover an area of $5,000 \mathrm{sq}$. ft. with a single-span roof, internal steel partitions being used to provide dark-rooms, etc. The absence of internal structural pillars and load-

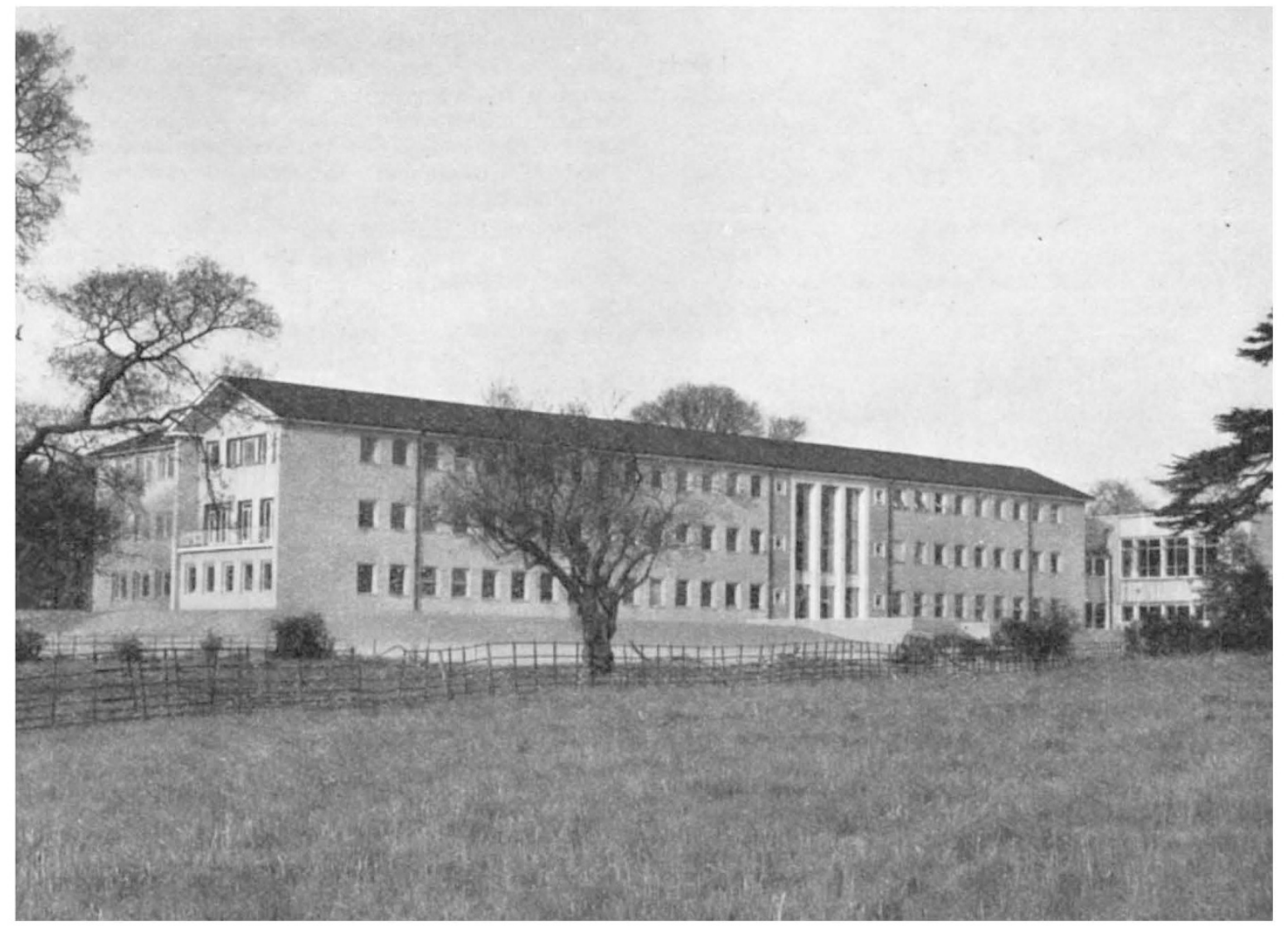

Fig. 1. The J. J. Thomson Physical Laboratory, Yniversity of Reading 
bearing walls enables the space to be utilized in a very economical way.

The larger lecture theatre contains seating for 180 and the smaller for 105 . Each has bench-type seating, specially modelled for maximum comfort, and fitted with hinged writing flaps. In each theatre the lecturer's demonstration bench is equipped with all laboratory services and, in addition, the electrically operated windows, blinds and dimming apparatus for the lighting can be controlled from it. The walls behind the demonstration benches are prepared to form a permanent projection surface $12 \mathrm{ft}$. wide and $6 \mathrm{ft}$. high, on which two pictures can be projected side by side. Below the projection surface is a 12-ft. glass chalk-board. On the left-hand side of the central wall is a splayed wall with a translucent glass chalk-board, which can be illuminated from behind when the room is darkened; on the right-hand side is another splayed wall fitted with a chalk-board of eonventional type.

Heating in the lecture theatres is by means of radiant wall panels combined with a heated aix plenum ventilation system. Elsewhere in the building heating is by 'Frenger' acoustic heated ceilings. All windows are double-glazed to reduce heat losses. Many of the rooms are provided with inlet and extract ventilation, particularly those fitted with dark blinds.

The main laboratory is planned on a repeating bay unit $7 \mathrm{ft} .6 \mathrm{in}$. wide and $16 \mathrm{ft}$. deep, with laboratory services arranged beneath the windows in a service rack. The services available in every bay of the building include alternating current supplies at $415 \mathrm{~V}$. (3-phass) and $240 \mathrm{~V}$. and $6 \mathrm{~V}$. (single phase) and direct current at $240 \mathrm{~V}$. and $24 \mathrm{~V}$. Hot and cold water, gas and compressed air are also available.

It was estimated that one and a half million gallons of cooling water per annum would be required for diffusion pumps, compressors, etc., and a recirculation system is therefore provided. This service is generally available in the centres of rooms, together with $240 \mathrm{~V}$. a.c. and one other service at choice.

Walls throughout the building are plastered and tinted and the doors are decorated in bright colours. The floors of most rooms are covered with 'Tarkett P.V.C.' tiles and the corridors with 'Korkoid'. The library has been designed to enable the beautiful surroundings of the Laboratory to be seen to advantage. Part of a gift from Imperial Chemical Industries, Ltd., has been used to provide books for the library, which will be especially useful during the next three years when the University Library is still on the old University site. Office accommodation for a theoretical physics group is provided near the library. This group is working on the application of quantum mechanics and statistical mechanies to problems in solid state physics, in particular crystal lattice vibrations, lattice imperfections and magneto-optic effects in semiconductors.

Most of the experimental work in the Laboratory is concerned with the physies of the solid state. One research group is studying the effects of imperfections in erystal structure on physical properties, particularly with reference to radiation damage (defects produced by irradiation with pile neutrons and other hign-energy particles). A 2-MeV. Van de Graaff generator (purchased with a grant from the Department of Scientific and Industrial Research) is used to produce defects in a controlled way. It is housed in a small building at a convenient distance from the main laboratory.

A section of the research space is assigned to the radio-tracer laboratory, which is mainly concerned with atomic diffusion in metals. This laboratory contains also a mass spectrometer which is used to assist biological as well as physical research.

A research group, supported by the Admiralty, is working on the surface properties of semiconductors. Methods of breaking germanium in a very high vacuum $\left(10^{-2}-10^{-10} \mathrm{~mm}\right.$. mercury) so as to expose a crystal plane have been devised, and the gradual contamination of these surfaces is being studied. Work on the etching of surfaces is being studied using high-quality optical microseopes, and an E.M.6 electron microscope is on order. Associated Electrical Industries, Ltd., have kindly agreed to provide a technical assistant to work this instrument for three years. Studies of solids by X-ray and electron diffraction are also in progress. The Royal Society has given a grant to assist the development of highvoltage electron diffraction using the Van de Graaff generator.

The Laboratory is equipped for spectroseopic studies for the infra-red, visible, ultra-violet and soft X-ray regions. The apparatus is used for measurements on solids chiefly in the infra-red and visible regions and in the vacuum ultra-violet. The results on gases have applications to studies on the upper atmosphere and to the physios of hot plasmas.

A biophysical investigation on vision is supported by the U.S. Public Health Service.

When the Laboratory was designed, the number of students in the University of Reading was expected to become stable at a figure in the range $1,500-2,000$. An increase to 3,000 is now contemplated. The Laboratory will have to provide for larger numbers in the Physics Department and also for the early development of at least two new departments in the physical sciences. The design of the building provided for possible extension which, it was thought, might be needed after twenty-five years. The nəw conditions have led to discussion of this extension even before the building was opened.

R. W. Ditchburn

\section{GOVERNING TECHNICAL COLLEGES}

HANDBOOK, "The Technical Colleges and their
Government", issued by the Joint Federation of
British Industries Technical Colleges Committee
under the auspices of the Federation's Education
Committee, provides a coneise but keen industrial appraisal of the structure of technical education, its historical background, academic pattern and finance as well as a close discussion of the government of technical colleges (pp. vii +44 . F.B.I. Handbook. London: Foderation of British Industries, 1960. 5s.). 